\title{
Panel-Reactive and Donor-Specific Antibodies before Lung Transplantation can Affect Outcomes in Korean Patients Receiving Lung Transplantation
}

\author{
Sung Woo Moon ${ }^{1}$, Moo Suk Park ${ }^{1}$, Jin Gu Lee ${ }^{2}$, Hyo Chae Paik ${ }^{2}$, Young Tae Kim³, Hyun Joo Lee ${ }^{3}$, \\ Samina Park ${ }^{3}$, Sun Mi Choi ${ }^{4}$, Do Hyung Kim ${ }^{5}$, Woo Hyun Cho ${ }^{6}$, Hye Ju Yeo ${ }^{6}$, Seung-il Park ${ }^{7}$, \\ Se Hoon Choi ${ }^{7}$, Sang-Bum Hong ${ }^{8}$, Tae Sun Shim ${ }^{8}$, Kyung-Wook Jo ${ }^{8}$, Kyeongman Jeon ${ }^{9}$, Byeong-Ho Jeong ${ }^{9}$, \\ Song Yee Kim; and the Korean Organ Transplantation Registry Study Group \\ ${ }^{1}$ Division of Pulmonology, Department of Internal Medicine, Yonsei University College of Medicine, Seoul; \\ ${ }^{2}$ Department of Thoracic and Cardiovascular Surgery, Severance Hospital, Yonsei University College of Medicine, Seoul; \\ ${ }^{3}$ Department of Thoracic and Cardiovascular Surgery, Seoul National University Hospital, Seoul National University College of Medicine, Seoul; \\ ${ }^{4}$ Division of Pulmonary and Critical Care Medicine, Department of Internal Medicine, Seoul National University Hospital, \\ Seoul National University College of Medicine, Seoul; \\ ${ }^{5}$ Department of Thoracic and Cardiovascular Surgery, Yangsan Hospital, Pusan National University School of Medicine, Yangsan; \\ ${ }^{6}$ Department of Pulmonology and Critical Care Medicine, Yangsan Hospital, Pusan National University School of Medicine, Yangsan; \\ ${ }^{7}$ Department of Thoracic and Cardiovascular Surgery, Asan Medical Center, University of Ulsan College of Medicine, Seoul; \\ ${ }^{8}$ Department of Pulmonology and Critical Care Medicine, Asan Medical Center, University of Ulsan College of Medicine, Seoul; \\ ${ }^{9}$ Division of Pulmonary and Critical Care Medicine, Department of Medicine, Samsung Medical Center, School of Medicine, \\ Sungkyunkwan University, Seoul, Korea.
}

Purpose: Data on the distribution and impact of panel reactive antibodies (PRA) and donor specific antibodies (DSA) before lung transplantation in Asia, especially multi-center-based data, are limited. This study evaluated the prevalence of and effects of PRA and DSA levels before lung transplantations on outcomes in Korean patients using nationwide multicenter registry data.

Materials and Methods: This study included 103 patients who received a lung transplant at five tertiary hospitals in South Korea between March 2015 and December 2017. Mortality, primary graft dysfunction (PGD), and bronchiolitis obliterans syndrome (BOS) were evaluated.

Results: Sixteen patients had class I and/or class II PRAs exceeding 50\%. Ten patients (9.7\%) had DSAs with a mean fluorescence intensity (MFI) higher than 1000, six of whom had antibodies with a high MFI ( $\geq 2000)$. DSAs with high MFIs were more frequently observed in patients with high-grade PGD $(\geq 2)$ than in those with no or low-grade $(\leq 1)$ PGD. In the 47 patients who survived for longer than 9 months and were evaluated for BOS after the transplant, BOS was not related to DSA or PRA levels. One-year mortality was more strongly related to PRA class I exceeding $50 \%$ than that under $50 \%$ ( $0 \%$ vs. $16.7 \%, p=0.007)$.

Conclusion: Preoperative DSAs and PRAs are related to worse outcomes after lung transplantation. DSAs and PRAs should be considered when selecting lung transplant recipients, and recipients who have preoperative DSAs with high MFI values and high PRA levels should be monitored closely after lung transplantation.

Key Words: Transplantation immunology, lung transplantation, primary graft dysfunction, bronchiolitis obliterans, mortality

Received: February 4, 2020 Revised: June 6, 2020 Accepted: June 8, 2020

Corresponding author: Song Yee Kim, MD, PhD, Division of Pulmonology, Department of Internal Medicine, Yonsei University College of Medicine, 50 Yonsei-ro, Seodaemun-gu, Seoul 03722, Korea.

Tel: 82-2-2228-1940, Fax: 82-2-393-6884, E-mail: dobie@yuhs.ac

The abstract of this paper was presented at "Asian Transplantation Week 2018," Nov 8-10, 2018, Bexco, Busan, Korea.

- The authors have no potential conflicts of interest to disclose.

(C) Copyright: Yonsei University College of Medicine 2020

This is an Open Access article distributed under the terms of the Creative Commons Attribution Non-Commercial License (https://creativecommons.org/licenses/by-nc/4.0) which permits unrestricted non-commercial use, distribution, and reproduction in any medium, provided the original work is properly cited. 


\section{INTRODUCTION}

Lung transplantation is an established treatment for patients with end-stage lung disease. The graft of an organ from a living or deceased donor in a recipient causes many immunological reactions, which in many cases results in failure of the allograft within the recipient's body. Whether grafts are destroyed by direct cytotoxicity mediated by cellular immune components, such as T cells and NK cells, delayed-type hypersensitivity reactions, or antibodies remains a critical question. ${ }^{1}$ Lung transplantation candidates may develop antibodies directed against human leukocyte antigens (HLA). Sensitization to polymorphic proteins, especially molecules of HLA classes I and II, can occur when a patient is exposed to cells from other individuals owing to pregnancy, transfusion, or transplantation. Immune sensitization before lung transplantation has been shown to be associated with increased alloreactivity and mortality following transplantation..$^{2-4}$

Allograft rejection is a serious complication following lung transplantation, leading to acute graft failure and, subsequently, chronic lung allograft dysfunction (CLAD) ${ }^{5}$ Bronchiolitis obliterans syndrome (BOS), the most common phenotype of CLAD, is the leading cause of late mortality and morbidity in lung recipients. ${ }^{5,6}$ Bronchiolitis obliterans is a small airway disease triggered by an insult to small airway epithelial and subepithelial cells, with the subsequent formation of excessive fibrosis and airway constriction. ${ }^{7}$ Furthermore, researchers have suggested that there is an immunologic link between CLAD and primary graft dysfunction (PGD) in the immediate post-lung transplant period. ${ }^{8} \mathrm{PGD}$ of the lung is a syndrome of "acute lung injury" that occurs within $72 \mathrm{~h}$ of lung transplantation. ${ }^{9}$ PGD contributes to nearly half of the short-term mortality rate after lung transplantation. ${ }^{10}$

In our previous study, we reported the prevalence of pretransplant anti-HLA antibodies and their impact on outcomes based on single center experience. ${ }^{11}$ However, data on the distribution and impact of panel reactive antibodies (PRA) and donor specific antibodies (DSA) before lung transplantation in Asia, especially multi-center based data, are limited, despite the increasing number of lung transplantations in the region. The Korean Organ Transplant Registry (KOTRY) was established in 2014 as a service of the Korean Centers for Disease Control, and it began to register cases of lung transplantation in 2015. ${ }^{12}$ It is the first nationwide multi-center registry for cases of lung transplantation in Korea. From the multi-center registry data, we sought 1) to investigate the prevalence of pre-transplant PRA and DSA levels in Korean patients prior to lung transplantation and 2) to determine how PRA and DSA levels before lung transplantation affects the development of PGD, BOS, and mortality in Korean patients receiving a lung transplant.

\section{MATERIALS AND METHODS}

\section{Study design and population}

Lung transplantation data from the KOTRY were derived from patients who received lung transplantation at one of five tertiary teaching hospitals (Asan Medical Center, Pusan National University Hospital, Samsung Medical Center, Seoul National University Hospital, and Severance Hospital) in South Korea starting from March 2015. Between March 2015 and December 2017, 112 patients received lung transplantation. Among these patients, one patient who received heart-lung transplantation and eight patients who did not undergo evaluation of their PRA and/or DSA levels were not checked before transplantation were excluded, and finally, 103 patients were included in the study. The follow-up was completed in June 2018.

\section{Clinical settings}

Transplantation was performed regardless of the status of DSA because of donor shortage as per a medical urgency-based allocation system in Korea (Supplementary Table 1, only online). ${ }^{13}$ Patients received induction therapy with high-dose steroid or IL-2 receptor antagonist, followed by standard triple immunosuppressive therapy consisting of the triple combination of calcineurin inhibitors, antiproliferative agents, and lowdose steroid after lung transplantation whenever this therapy was not contraindicated. Pre-transplant immunological results did not affect the choice of immunosuppressant regimen.

\section{Collected data and clinical outcomes}

Information about the transplant recipients, donors, transplant operations, and postoperative follow-up results were prospectively collected. Data on recipients, including general demographic information, primary diagnosis, and pre-transplantation status, performance of desensitization protocol, and data on donors, including general demographic information, cause of brain death, and smoking status, were collected. KOTRY also includes data on post-transplantation results, including immediate complications, need for organ support, prevalence of PGD, serial pulmonary function $(3,6,9,12$, and 24 months after lung transplantation), and outcomes, such as the length of hospital stay, in-hospital and 6-month mortality, function status at discharge, and co-morbidities. The most recent information for each patient was collected at 3, 6, 9, and 12 months after discharge, and then annually thereafter. The follow-up data were collected by the attending physician and stored using a web-based case report form.

Furthermore, all patients included in the study underwent PRA class I and II identification or single antigen assays (One lambda, Inc., West Hills, CA, USA or Gen-Probe Inc., San Diego, CA, USA) before lung transplantation. Anti-HLA antibodies against donor HLA were defined as DSAs. DSAs were quantified based on mean fluorescence intensity (MFI), and the highest MFI value was recorded. The DSAs were classified 
based on MFI as follows: $\mathrm{MFI}<1000,1000 \leq \mathrm{MFI}<2000$, and $>2000$.

Clinical outcomes included PGD, BOS, and death within 1 year after transplantation. PGD after lung transplantation represents an injury to the transplanted lung that develops in the first $72 \mathrm{~h}$ after the transplantation. The diagnosis and grading of PGD were based on the ratio of arterial oxygen pressure to the inspired oxygen concentration, as well as the presence of infiltration on chest radiographs, according to the International Society for Heart and Lung Transplantation (ISHLT) criteria. ${ }^{14}$ BOS was identified as a progressive decline in forced expiratory volume in $1 \mathrm{~s}\left(\mathrm{FEV}_{\mathrm{l}}\right)$ after excluding other etiologies. BOS was diagnosed according to the ISHLT criteria. BOS was defined as a $>20 \%$ decrease in $\mathrm{FEV}_{1}$ from baseline. A potential BOS stage was defined as a $10-19 \%$ decrease in $\mathrm{FEV}_{1}$ and/or a $\geq 25 \%$ decrease in $\mathrm{FEF}_{25-75}$ from baseline. ${ }^{15,16}$ The development of BOS was evaluated in patients who survived for longer than 9 months.

\section{Statistical analysis}

Descriptive statistics are reported as a number with proportions or medians with min-max values. Fisher's exact test was used to compare categorical variables between two groups. The Mann-Whitney U test was used to compare continuous variables between the two groups. Multivariate logistic regression models with backward variable selection were used to estimate the odds ratios for death within 1 year after transplantation while controlling for age and sex. The Kaplan-Meier method was used to compare survival based on pre-transplant calculated panel-reactive antibody (cPRAs) and DSAs. All statistical analyses were performed using SPSS version 25.0 (IBM Corp., Armonk, NY, USA). A $p$ value of $<0.05$ was considered statistically significant.

\section{Ethics statement}

Written informed consent is obtained from each patient prior to transplantation. If patients are unable to provide consent due to disease severity, informed consent is obtained from a relative or legal representative. This KOTRY study was reviewed and approved by the Institutional Ethics Committees of each participating organization including the Institutional Review Board of Severance Hospital (IRB no. 4-2018-1187).

\section{RESULTS}

\section{Baseline characteristics}

The baseline characteristics of the recipients according to the

Table 1. Characteristics of Recipients With or Without Donor-Specific Antibodies

\begin{tabular}{|c|c|c|c|c|}
\hline & \multirow{2}{*}{ All } & \multicolumn{2}{|c|}{ Donor-specific antibody } & \multirow{2}{*}{$p$ value } \\
\hline & & No (n=93) & Yes $(n=10)$ & \\
\hline Age (yr) & $58(25-73)$ & $58(25-73)$ & $55(44-62)$ & 0.262 \\
\hline Male & $65(63.1)$ & $63(67.7)$ & $2(20)$ & 0.005 \\
\hline $\operatorname{BMI}\left(\mathrm{kg} / \mathrm{m}^{2}\right)$ & $21.2(12.3-29.0)$ & $21.3(12.3-29.0)$ & $19.8(14.4-24.8)$ & 0.612 \\
\hline ABO blood type & & & & 0.017 \\
\hline A & $41(39.8)$ & $38(40.9)$ & $3(30)$ & \\
\hline B & $25(24.3)$ & $25(26.9)$ & $0(0)$ & \\
\hline$A B$ & $12(11.7)$ & $8(8.6)$ & $4(40)$ & \\
\hline 0 & $25(24.3)$ & $22(23.7)$ & $3(30)$ & \\
\hline Primary diagnosis & & & & 0.220 \\
\hline COPD & $4(3.9)$ & $4(4.3)$ & $0(0)$ & \\
\hline Idiopathic pulmonary fibrosis & $56(54.4)$ & $53(57.0)$ & $3(30)$ & \\
\hline Idiopathic pulmonary artery hypertension & $1(1.0)$ & $1(1.1)$ & $0(0)$ & \\
\hline Bronchiectasis & $3(2.9)$ & $2(2.2)$ & $1(10)$ & \\
\hline Bronchiolitis obliterans syndrome after HSCT & $10(9.7)$ & $10(10.8)$ & $0(0)$ & \\
\hline Connective tissue disease related ILD & $17(16.5)$ & $14(15.1)$ & $3(30)$ & \\
\hline Lymphangioleiomyomatosis & $2(1.9)$ & $2(2.2)$ & $0(0)$ & \\
\hline Others* & $10(9.7)$ & $7(7.5)$ & $3(30)$ & \\
\hline Smoking & & & & 0.317 \\
\hline Ever smoker & $50(48.5)$ & $47(50.5)$ & $3(30)$ & \\
\hline$<20$ pack-years & $15(14.6)$ & $13(14.0)$ & $2(20)$ & \\
\hline$\geq 20$ pack-years & $35(34.9)$ & $34(36.5)$ & $1(10)$ & \\
\hline Never smoker & $53(51.5)$ & $46(49.5)$ & $7(70)$ & \\
\hline Bilateral lung transplantation & $99(96.1)$ & $90(96.8)$ & $9(90)$ & 0.340 \\
\hline
\end{tabular}

BMI, body mass index; COPD, chronic obstructive pulmonary disease; HSCT, hematopoietic stem cell transplantation; ILD, interstitial lung disease. Values are presented as the median (min-max) or number of patients (\%).

${ }^{*}$ Acute respiratory distress syndrome, eisenmenger syndrome. 
presence of DSAs are shown in Table 1. Ten patients (9.7\%) had DSAs before lung transplantation. The median patient age was 58 years ( $\min 25$, max 78 years), and 65 recipients (63.1\%) were male. The primary diagnosis was idiopathic pulmonary fibrosis in 56 cases (54.4\%), chronic obstructive pulmonary disease in four cases (3.9\%), idiopathic pulmonary artery hypertension in one case (1.0\%), bronchiectasis in three cases (2.9\%), BOS after stem cell transplantation in 10 cases (9.7\%), interstitial lung disease with connective tissue disease in 17 cases (16.5\%), lymphangioleiomyomatosis in two cases (1.9\%), and other diseases in 10 cases (9.7\%). The proportion of patients who were male or had $\mathrm{ABO}$ blood type $\mathrm{B}$ was higher in the group of patients who did not have DSAs than in the group of patients with DSAs.

Table 2. Prevalence of Pre-Transplant Panel-Reactive and Donor-Specific Antibodies

\begin{tabular}{|c|c|c|c|}
\hline Variable & Total & Class I* & Class II $^{\dagger}$ \\
\hline \multicolumn{4}{|c|}{ Calculated panel-reactive antibody } \\
\hline Not detected & $47(45.6)$ & $62(60.2)$ & $70(68.0)$ \\
\hline PRA $<50 \%$ & $40(38.9)$ & $34(33.0)$ & $24(23.3)$ \\
\hline PRA $\geq 50 \%$ & $16(15.5)$ & $7(6.8)$ & $9(8.7)$ \\
\hline \multicolumn{4}{|c|}{ Donor-specific antibody MFI } \\
\hline$<1000$ & $93(90.3)$ & 98 (95.1) & $97(94.2)$ \\
\hline $1000-2000$ & $4(3.9)$ & $2(1.9)$ & $2(1.9)$ \\
\hline$\geq 2000$ & $6(5.8)$ & $3(2.9)$ & $4(3.9)$ \\
\hline
\end{tabular}

PRA, panel reactive antibodies; $\mathrm{MFI}$, mean fluorescence intensity. Values are presented as the number of patients (\%).

${ }^{*} H L A-A, H L A-B$, and HLA-C, ${ }^{+} H L A-D O$ and HLA-DR.
The prevalence of cPRAs and DSAs are shown in Table 2. Among the patients, high levels of class I or II cPRAs ( $\geq 50 \%)$ were detected in 16 patients (15.5\%), low levels of class I and/ or II cPRAs ( $<50 \%)$ were detected in 40 patients $(38.9 \%)$, and cPRAs were not detected in 47 patients (45.6\%). In terms of the distribution of MFIs of DSAs, four patients (3.9\%) had antiHLA antibodies with MFI of 1000-2000, and six (5.8\%) had an MFI higher than 2000.

The characteristics of 10 patients who had DSAs are shown in Table 3. Among the 10 patients, four patients underwent a desensitization process before lung transplantation. Of these four patients, three died within 1 year after the lung transplantation, and the remaining one patient had grade 3 BOS (patient number 1). Among the six patients who did not undergo desensitization, three patients (patient number 5,8 , and 9) had MFIs higher than 2000, of whom two patients (patient number 5 and 9) survived for over 1 year and did not develop highgrade BOS. Among the four patients (patient number 3, 6, 8, and 10) who died within 1 year, two patients (patient number 3 and 8) died of respiratory failure.

\section{Outcomes}

As shown in Table 4, patients were divided into two groups based on PGD grade: grade 0-1, non-high-grade PGD group, and grade $\geq 2$, high-grade PGD. Twenty-two patients (21.4\%) developed high-grade PGD. Furthermore, high-grade PGD developed more frequently in patients with DSAs that had MFI values higher than 2000 than in patients with DSAs that had MFI values lower than $2000(p=0.029)$. A high cPRAs $(\geq 50 \%)$

Table 3. Characteristics of Patients with Donor-Specific Antibodies with MFI $\geq 1000$

\begin{tabular}{|c|c|c|c|c|c|c|c|c|}
\hline Pt. & $\begin{array}{c}\text { Sex/age } \\
\text { (yr) }\end{array}$ & DSA (MFI) & $\begin{array}{c}\text { cPRA } \\
(\%)\end{array}$ & Desensitization & $\begin{array}{l}\text { PGD } \\
\text { grade }\end{array}$ & BOS & $\begin{array}{l}\text { Death within } \\
1 \text { year after lung } \\
\text { transplantation }\end{array}$ & Cause of death \\
\hline 1 & Female/47 & $\begin{array}{l}\text { DR12 (2920) } \\
\text { DR15 (2920) } \\
\text { DR } 52(6078)\end{array}$ & 100 & Yes & 1 & BOS grade 3 & No & - \\
\hline 2 & Male/52 & A11 (1246) & 0 & No & 0 & BOS grade 1 & No & - \\
\hline 3 & Female/59 & $\begin{array}{l}\text { A2 (3046) } \\
\text { B44 (11669) } \\
\text { DR8 (1414) }\end{array}$ & 6 & Yes & 2 & $N / A^{*}$ & Yes & Asphyxia \\
\hline 4 & Female/62 & D07 (1300) & 28 & No & 0 & $\mathrm{~N} / \mathrm{A}^{*}$ & $\mathrm{~N} / \mathrm{A}^{\dagger}$ & - \\
\hline 5 & Female/59 & $\begin{array}{l}\text { DR14 (3150) } \\
\text { DR52 (2600) }\end{array}$ & 98 & No & 3 & No & No & - \\
\hline 6 & Female/44 & $\begin{array}{l}\text { B35(11037) } \\
\text { B13 (8306) }\end{array}$ & 75 & Yes & 0 & $N / A^{*}$ & Yes & Unknown \\
\hline 7 & Female/56 & DR52 (1160) & 0 & No & 0 & No & No & - \\
\hline 8 & Male/61 & B44 (5026) & 61 & No & 2 & $N / A^{*}$ & Yes & Respiratory failure \\
\hline 9 & Female/53 & DR4 (7180) & 44 & No & 3 & BOS grade Op & No & - \\
\hline 10 & Female/54 & $\begin{array}{l}\text { B13 (379) } \\
\text { B48 (2937) }\end{array}$ & 56 & Yes & 0 & $N / A^{*}$ & Yes & Unknown \\
\hline
\end{tabular}

$\mathrm{MFI}$, mean fluorescence intensity; cPRA, calculated panel-reactive antibody; PGD, primary graft dysfunction; BOS, bronchiolitis obliterans syndrome; N/A, not applicable.

${ }^{*}$ Could not perform pulmonary function test sufficiently to evaluate BOS, 'Was not followed-up up to 1 year. 
Table 4. Association of Pre-Transplant Panel-Reactive and Donor-Specific Antibodies with Primary Graft Dysfunction Status

\begin{tabular}{|c|c|c|c|}
\hline & $\begin{array}{c}\text { PGD 0-1 } \\
(n=81)\end{array}$ & $\begin{array}{c}\text { PGD 2-3 } \\
(n=22)\end{array}$ & $p$ value \\
\hline \multicolumn{4}{|l|}{ Total } \\
\hline CPRA & & & 0.743 \\
\hline Not detected or cPRA <50\% & $69(85.2)$ & $18(81.8)$ & \\
\hline$c P R A \geq 50 \%$ & 12 (14.8) & $4(18.2)$ & \\
\hline Donor-specific antibody MFI & & & 0.029 \\
\hline$<1000$ & $75(92.6)$ & 18 (81.8) & \\
\hline 1000-2000 & $4(4.9)$ & $0(0)$ & \\
\hline$\geq 2000$ & $2(2.5)$ & $4(18.2)$ & \\
\hline \multicolumn{4}{|l|}{ Class I } \\
\hline cPRA & & & $>0.999$ \\
\hline Not detected or cPRA $<50 \%$ & $75(92.6)$ & $21(95.5)$ & \\
\hline$c P R A \geq 50 \%$ & $6(7.4)$ & $1(4.5)$ & \\
\hline Donor-specific antibody MFI & & & 0.154 \\
\hline$<1000$ & $78(96.3)$ & 20 (90.9) & \\
\hline 1000-2000 & $2(2.5)$ & $0(0)$ & \\
\hline$\geq 2000$ & $1(1.2)$ & $2(9.1)$ & \\
\hline \multicolumn{4}{|l|}{ Class II } \\
\hline CPRA & & & 0.398 \\
\hline Not detected or cPRA <50\% & 75 (92.6) & 19 (86.4) & \\
\hline$c P R A \geq 50 \%$ & $6(7.4)$ & $3(13.6)$ & \\
\hline Donor-specific antibody MFI & & & 0.036 \\
\hline$<1000$ & $78(96.3)$ & $19(86.4)$ & \\
\hline 1000-2000 & $2(2.5)$ & $0(0)$ & \\
\hline$\geq 2000$ & $1(1.2)$ & $3(13.6)$ & \\
\hline
\end{tabular}

CPRA, calculated panel-reactive antibody; MFI, mean fluorescence intensity. Values are presented as the number of patients (\%).

was not associated with the development of high-grade PGD for both class I and II antibodies.

As shown in Table 5, patients were divided into two groups based on BOS grade: grade 0-0p, non-BOS; and grade $\geq 1$, BOS. Forty-seven patients who survived longer than 9 months after the lung transplantation and underwent regular pulmonary function tests were evaluated. Among the 47 patients, the median follow-up time was 27.5 months ( $\min 5.6$ months and max 38.6 months), and BOS developed in 10 patients (21.3\%). BOS development was not related to cPRA or the MFI of DSAs for both class I and II antibodies.

There was no significant difference in survival rates when stratified by pre-transplant cPRAs and DSAs according to analysis of Kaplan-Meier survival curves (Fig. 1). The association between pre-transplant anti-HLA antibodies and death within 1 year after transplantation is shown in Table 6. Among the 103 patients, data regarding death within 1 year after transplantation were available for 78 patients. In total, high cPRA levels $(p=0.050)$ and MFIs of DSAs $(p=0.719)$ were not related to death within 1 year after transplantation. However, when considering only class I anti-HLA antibodies, high cPRA levels ( $p=0.007)$ were related to death within 1 year after transplan-
Table 5. Associations of Pre-Transplant Panel Reactive and DonorSpecific Antibodies with BOS Status

\begin{tabular}{|c|c|c|c|}
\hline & $\begin{array}{c}\text { BOSO, Op } \\
(n=37)\end{array}$ & $\begin{array}{c}\geq \text { BOS } 1 \\
(n=10)\end{array}$ & $p$ value \\
\hline \multicolumn{4}{|l|}{ Total } \\
\hline cPRA & & & $>0.999$ \\
\hline Not detected or cPRA $<50 \%$ & 34 (91.9) & $9(90)$ & \\
\hline$c P R A \geq 50 \%$ & $3(8.1)$ & $1(10)$ & \\
\hline Donor-specific antibody MFI & & & 0.285 \\
\hline$<1000$ & 34 (91.9) & $8(80)$ & \\
\hline 1000-2000 & $1(2.7)$ & $1(10)$ & \\
\hline$\geq 2000$ & $2(5.4)$ & $1(10)$ & \\
\hline \multicolumn{4}{|l|}{ Class I } \\
\hline CPRA & & & $\mathrm{N} / \mathrm{A}$ \\
\hline Not detected or cPRA $<50 \%$ & $37(100)$ & $10(100)$ & \\
\hline$c P R A \geq 50 \%$ & $0(0)$ & $0(0)$ & \\
\hline Donor-specific antibody MFI & & & 0.213 \\
\hline$<1000$ & $37(100)$ & $9(90)$ & \\
\hline 1000-2000 & $0(0)$ & $1(10)$ & \\
\hline$\geq 2000$ & $0(0)$ & $0(0)$ & \\
\hline \multicolumn{4}{|l|}{ Class II } \\
\hline cPRA & & & $>0.999$ \\
\hline Not detected or cPRA $<50 \%$ & $34(91.9)$ & $9(90)$ & \\
\hline$c P R A \geq 50 \%$ & $3(8.1)$ & $1(10)$ & \\
\hline Donor-specific antibody MFI & & & 0.630 \\
\hline$<1000$ & 34 (91.9) & $9(90)$ & \\
\hline 1000-2000 & $1(2.7)$ & $0(0)$ & \\
\hline$\geq 2000$ & $2(5.4)$ & $1(10)$ & \\
\hline
\end{tabular}

BOS, bronchiolitis obliterans syndrome; cPRA, calculated panel-reactive antibody; MFI, mean fluorescence intensity; N/A, not applicable.

Forty-seven patients survived for longer than 9 months after lung transplantation and underwent pulmonary function test for chronic lung allograft dysfunction.

Values are presented as the number of patients (\%).

tation, and although not statistically significant, death within 1 year after transplantation was more frequent in patients who had MFIs of DSAs higher than 2000 ( $p=0.053$ ). Supplementary Table 2 (only online) shows the results of the multivariate logistic regression analysis for factors contributing to death within 1 year after transplantation. When age and sex were included in the regression model, high cPRA levels in class I (odds ratio: 3.558, 95\% confidence interval: 0.941-13.446, $p=$ 0.061 ) tend to be related with death within 1 year after transplantation, although statistical significance was not observed.

\section{DISCUSSION}

The major strength of this study was that it was a nationwide study using thoroughly collected data, enhancing our ability to generalize the study results. The KOTRY allowed investigation of the prevalence of PRA and DSA levels in Korean lung transplantation patients prior to lung transplant and how PRA 

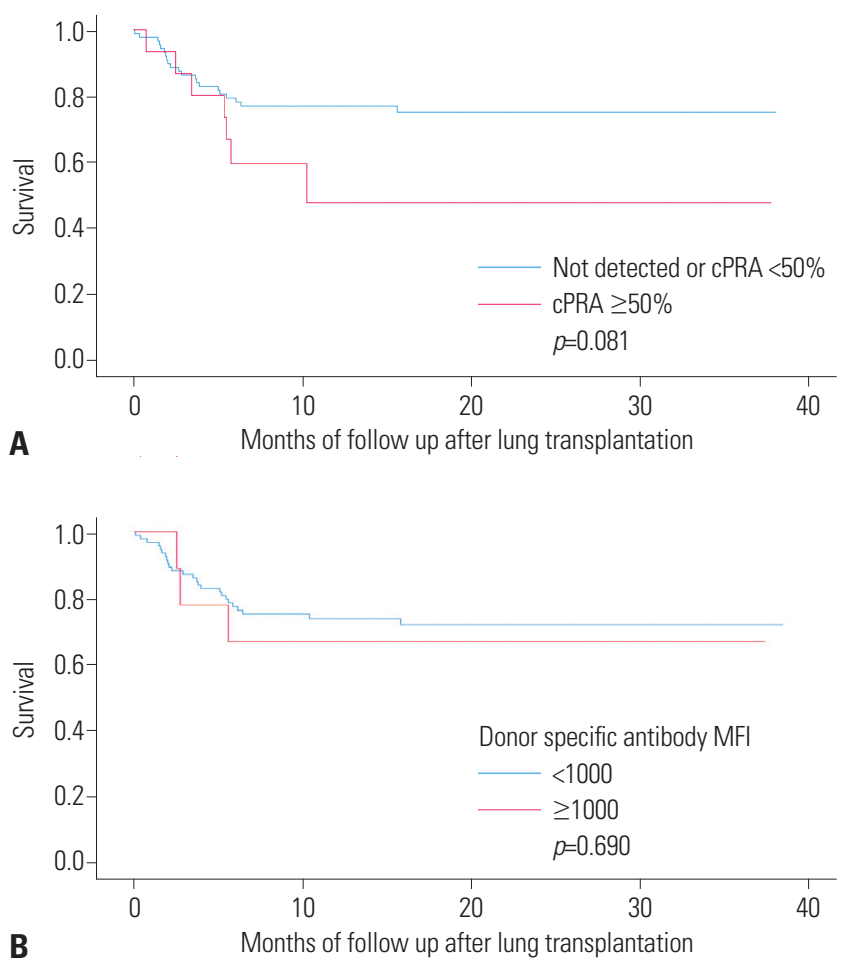

Fig. 1. Kaplan-Meier survival curves stratified by pre-transplant panel-reactive antibodies (A) and donor-specific antibodies (B). cPRA, calculated panel-reactive antibody; MFI, mean fluorescence intensity.

and DSA levels before lung transplantation are related to patient outcomes. A high level of DSAs was related to high-grade PGD, and class I cPRA levels exceeding 50\% were related to a higher number of deaths within 1 year after transplantation.

In this nationwide registry, the prevalences of high cPRA ( $\geq 50 \%$ ) (class I, $6.8 \%$; class II, $8.7 \%$; total, $15.5 \%$ ) and DSA (MFI $\geq 1000$ ) (class I, $4.8 \%$; class II $5.8 \%$; total $9.7 \%$ ) levels were comparable to data for Western countries. In a study performed in Belgium, $17 \%$ of the patients had MFIs for DSAs higher than 500 , as detected by the Luminex assay. ${ }^{17}$ In a study performed in France, $89 \%$ of the patients had either anti-HLA class I or II antibodies, and $32 \%$ had DSA (MFIs higher than 300 ), as detected by the Luminex assay. ${ }^{18}$ Additionally, in a single center study performed in the United States, $8.9 \%$ of the patients had DSA with MFIs greater than 1000, as detected by the Luminex assay. There were inconsistencies between the data from Belgium and France and data from the United States and this study; however, these inconsistencies may be attributable to differences in MFI cutoffs. The proportion of patients with a high cPRA ( $>50 \%$ ) (class I, $7.9 \%$; class II, $5.3 \%$; total, $11.8 \%$ ) in our previous single-center study was similar to that in a multi-center study. ${ }^{11}$

Although a relationship between PGD and DSAs has been previously shown and studies have investigated the association between BOS and anti-HLA antibodies, the relationship between BOS and anti-HLA antibodies is unclear. ${ }^{19-21}$ BOS and anti-HLA antibodies were not found to be related in this study
Table 6. Associations for Pre-Transplant Panel-Reactive and DonorSpecific Antibodies with Death Within 1 Year

\begin{tabular}{|c|c|c|c|}
\hline & $\begin{array}{l}\text { Survival for } \\
\text { more than } \\
1 \text { year }(n=48)\end{array}$ & $\begin{array}{c}\text { Death } \\
\text { within } \\
1 \text { year }(n=30)\end{array}$ & $p$ value \\
\hline \multicolumn{4}{|l|}{ Total } \\
\hline CPRA & & & 0.050 \\
\hline Not detected or cPRA $<50 \%$ & $44(91.7)$ & 22 (73.3) & \\
\hline$c P R A \geq 50 \%$ & $4(8.3)$ & $8(26.7)$ & \\
\hline Donor-specific antibody MFI & & & 0.719 \\
\hline$<1000$ & 44 (91.7) & $26(86.7)$ & \\
\hline 1000-2000 & $2(4.2)$ & $1(3.3)$ & \\
\hline$\geq 2000$ & $2(4.2)$ & $3(10)$ & \\
\hline \multicolumn{4}{|l|}{ Class I } \\
\hline cPRA & & & 0.007 \\
\hline Not detected or cPRA $<50 \%$ & $48(100)$ & $25(83.3)$ & \\
\hline$c P R A \geq 50 \%$ & $0(0)$ & $5(16.7)$ & \\
\hline Donor-specific antibody MFI & & & 0.053 \\
\hline$<1000$ & $47(97.9)$ & $26(86.7)$ & \\
\hline 1000-2000 & $1(2.1)$ & $1(3.3)$ & \\
\hline$\geq 2000$ & $0(0)$ & $3(10)$ & \\
\hline \multicolumn{4}{|l|}{ Class II } \\
\hline CPRA & & & $>0.999$ \\
\hline Not detected or cPRA $<50 \%$ & $44(91.7)$ & $27(90)$ & \\
\hline$c P R A \geq 50 \%$ & $4(8.3)$ & $3(10)$ & \\
\hline Donor-specific antibody MFI & & & $>0.999$ \\
\hline$<1000$ & 45 (93.8) & $29(96.7)$ & \\
\hline 1000-2000 & $1(2.1)$ & $0(0)$ & \\
\hline$\geq 2000$ & $2(4.2)$ & $1(3.3)$ & \\
\hline
\end{tabular}

cPRA, calculated panel-reactive antibody; MFI, mean fluorescence intensity. Values are presented as the number of patients $(\%)$.

probably because we were only able to analyze the presence of BOS in only 47 patients, and among them, only 10 had BOS. Further, the follow-up duration was relatively short. A more accurate assessment would be possible if further data of transplant patients are accumulated. Furthermore, PGD has multifactorial causes, and based on previous studies, as well as the results of this study, an immunological response may be one of the mechanisms of PGD. ${ }^{22}$ Furthermore, PGD is considered a risk factor for CLAD ${ }^{23}$; therefore, PGD being related to antiHLA antibodies could imply an immunological link between CLAD and PGD in the immediate post-lung transplantation period. ${ }^{8}$

The cut-off values for cPRA and DSA MFI in lung transplantation patients differ among studies. ${ }^{18-22}$ This study used cutoff values of $50 \%$ for cPRAs and 1000 and 2000 for DSA MFI. The Stanford pre-lung transplant HLA antibody management protocol recommends intervention if cPRA values are higher than $50 \% .{ }^{24}$ Some labs define DSA MFI $>1000$ as DSA-positive, while some consider DSA MFI $>2000$ to be clinically significant DSA-positive. ${ }^{25}$ Further studies including prospective studies are needed to clarify the cut-off point for lung trans- 
plantation patients.

This study showed differences in 1-year mortality between patients with HLA class I and II antibodies. There is growing evidence that class I and II antibodies are associated with clinically different outcomes. ${ }^{26}$ In patients undergoing renal transplantation, the presence and level of class II DSAs and its level at the time of transplantation are associated with worse outcomes, while that of class I DSA is not. ${ }^{27}$ However, we cannot confirm if our results were different because a different organ was studied or because of other reasons; therefore, further studies in this regard are needed.

In this study, desensitization was performed in only four out of 10 patients with DSA of moderate to high MFIs; however, the prognosis of patients who underwent desensitization was poor. Desensitization for each patient was based on the clinical practice of the individual center rather than the trial protocol. The Toronto Lung Transplant Program developed a protocol for the management of sensitized transplant candidates guiding organ allocation, perioperative desensitization, and maintenance immunotherapy. ${ }^{28}$ However, evidence on the efficacy of desensitization in patients undergoing lung transplantation are insufficient. ${ }^{17,29}$ In the study by Snyder, et al., ${ }^{30}$ an aggressive multi-modal desensitization protocol that included plasmapheresis, steroids, bortezomib, and rituximab did not significantly reduce the levels of pre-transplant HLA antibodies. Further studies are required to examine the efficacy and indication of desensitization in patients with high levels of cPRAs or DSAs before lung transplantation.

As mentioned earlier, sensitization to HLA class I and II molecules can occur when a patient is exposed to cells from other individuals due to pregnancy, transfusion, or transplantation. ${ }^{29,31,32}$ This may explain why the prevalence of DSAs was higher in female patients. ${ }^{33}$ Furthermore, sensitizing events, such as blood transfusions, which result in the accumulation of pre-transplant antibodies, should be avoided as much as clinically feasible. The majority of patients receive at least three units of red blood cells in the perioperative period. ${ }^{34}$ Blood transfusion before lung transplantation is known to be a negative predictive factor and is associated with transfusion-related acute lung injury and transfusion-associated circulatory overload, pneumonia, and Epstein-Barr virus infection. ${ }^{34,35}$

Our study had some limitations. First, this was a relatively small retrospective study with a short follow-up period. Thus, adjustment for many prognostic factors that could affect survival among lung transplantation patients could not be performed in this study. However, this was the first multi-institutional attempt to evaluate the impact of anti-HLA antibodies in Korean patients using nationwide lung transplantation cohort data. Second, post-transplant DSAs were not routinely checked or included in the analysis. Moreover, restrictive allograft syndrome, a form of CLAD other than BOS, was surveyed but could not be included in this study because only two patients showed a restrictive allograft syndrome phenotype.
Third, donor lungs are allocated to the most urgent cases based on the Korean Network for Organ Sharing urgency status instead of the lung allocation score system, which is the most widely used allocation system in the world.

In conclusion, KOTRY data were used to demonstrate how PRA and DSA levels before lung transplantation are related to outcomes in the Korean population. High levels of DSAs were related to high-grade PGD, and a PRA class I level exceeding $50 \%$ was related to 1-year mortality. DSA and PRA levels should be considered in selecting lung transplantation recipients, and recipients who have high preoperative DSA MFIs and PRA should be monitored closely after lung transplantation.

\section{ACKNOWLEDGEMENTS}

This research was supported by funds (2014-ER6301-00, 2014ER6301-01, 2014-ER6301-02, 2017-ER6301-00) from the Research of Korea Centers for Disease Control and Prevention.

\section{AUTHOR CONTRIBUTIONS}

Conceptualization: Sung Woo Moon and Song Yee Kim. Data curation: all authors. Formal analysis: Sung Woo Moon. Funding acquisition: Song Yee Kim. Investigation: all authors. Methodology: Sung Woo Moon and Song Yee Kim. Project administration: Song Yee Kim. Resources: all authors. Software: all authors. Supervision: Song Yee Kim. Validation: all authors. Visualization: Sung Woo Moon and Song Yee Kim. Writing_-original draft: Sung Woo Moon and Song Yee Kim. Writing—review \& editing: all authors. Approval of final manuscript: all authors.

\section{ORCID iDs}

Sung Woo Moon Moo Suk Park Jin Gu Lee Hyo Chae Paik Young Tae Kim Hyun Joo Lee Samina Park Sun Mi Choi Do Hyung Kim Woo Hyun Cho Hye Ju Yeo Seung-il Park Se Hoon Choi Sang-Bum Hong Tae Sun Shim Kyung-Wook Jo Kyeongman Jeon Byeong-Ho Jeong Song Yee Kim https://orcid.org/0000-0001-9917-9802 https://orcid.org/0000-0003-0820-7615 https://orcid.org/0000-0003-2767-6505 https://orcid.org/0000-0001-9309-8235 https://orcid.org/0000-0001-9006-4881 https://orcid.org/0000-0002-3092-2167 https://orcid.org/0000-0001-9625-2672 https://orcid.org/0000-0002-0742-6085 https://orcid.org/0000-0002-8774-3397 https://orcid.org/0000-0002-8299-8008 https://orcid.org/0000-0002-8403-5790 https://orcid.org/0000-0002-8729-0498 https://orcid.org/0000-0002-9961-9289 https://orcid.org/0000-0003-2737-7695 https://orcid.org/0000-0001-6653-816X https://orcid.org/0000-0002-5949-248X https://orcid.org/0000-0002-4822-1772 https://orcid.org/0000-0002-3124-1718 https://orcid.org/0000-0001-8627-486X

\section{REFERENCES}

1. Ravindranath MH, Cai J, Ferrone S, Claas FHJ, Selvan SR. The humoral theory of transplantation. J Immunol Res 2017;2017: 5935123. 
2. Hadjiliadis D, Chaparro C, Reinsmoen NL, Gutierrez C, Singer LG, Steele MP, et al. Pre-transplant panel reactive antibody in lung transplant recipients is associated with significantly worse post-transplant survival in a multicenter study. J Heart Lung Transplant 2005;24:S249-54.

3. Shah AS, Nwakanma L, Simpkins C, Williams J, Chang DC, Conte JV. Pretransplant panel reactive antibodies in human lung transplantation: an analysis of over 10,000 patients. Ann Thorac Surg 2008;85:1919-24.

4. Hayes D Jr, Tumin D, Tobias JD. Pre-transplant panel reactive antibody and survival in adult cystic fibrosis patients after lung transplantation. Lung 2016;194:429-35.

5. Costa J, Benvenuto LJ, Sonett JR. Long-term outcomes and management of lung transplant recipients. Best Pract Res Clin Anaesthesiol 2017;31:285-97.

6. Sundaresan S, Trulock EP, Mohanakumar T, Cooper JD, Patterson GA. Prevalence and outcome of bronchiolitis obliterans syndrome after lung transplantation. Washington University Lung Transplant Group. Ann Thorac Surg 1995;60:1341-6; discussion 1346-7.

7. Thomas L, Hachem R. Bronchiolitis Obliterans Syndrome (BOS) following lung transplant. Am J Respir Crit Care Med 2016;193: P19-20.

8. Bharat A, Kuo E, Steward N, Aloush A, Hachem R, Trulock EP, et al. Immunological link between primary graft dysfunction and chronic lung allograft rejection. Ann Thorac Surg 2008;86:189-95; discussion 196-7.

9. Kotsimbos T, Williams TJ, Anderson GP. Update on lung transplantation: programmes, patients and prospects. Eur Respir Rev 2012;21:271-305.

10. Christie JD, Kotloff RM, Ahya VN, Tino G, Pochettino A, Gaughan $\mathrm{C}$, et al. The effect of primary graft dysfunction on survival after lung transplantation. Am J Respir Crit Care Med 2005;171:1312-6.

11. Park JE, Kim CY, Park MS, Song JH, Kim YS, Lee JG, et al. Prevalence of pre-transplant anti-HLA antibodies and their impact on outcomes in lung transplant recipients. BMC Pulm Med 2018; 18:45.

12. Lee JG, Kim SY, Kim YT, Lee HJ, Park S, Choi SM, et al. First report of the Korean lung transplantation registry. Transplant Proc 2018; 50:2759-63.

13. Yu WS, Kim SY, Kim YT, Lee HJ, Park S, Choi SM, et al. Characteristics of lung allocation and outcomes of lung transplant according to the Korean urgency status. Yonsei Med J 2019;60:992-7.

14. Christie JD, Edwards LB, Kucheryavaya AY, Benden C, Dipchand AI, Dobbels F, et al. The Registry of the International Society for Heart and Lung Transplantation: 29th adult lung and heart-lung transplant report-2012. J Heart Lung Transplant 2012;31:1073-86.

15. Meyer KC, Raghu G, Verleden GM, Corris PA, Aurora P, Wilson $\mathrm{KC}$, et al. An international ISHLT/ATS/ERS clinical practice guideline: diagnosis and management of bronchiolitis obliterans syndrome. Eur Respir J 2014;44:1479-503.

16. Verleden GM, Glanville AR, Lease ED, Fisher AJ, Calabrese F, Corris PA, et al. Chronic lung allograft dysfunction: definition, diagnostic criteria, and approaches to treatment-a consensus report from the Pulmonary Council of the ISHLT. J Heart Lung Transplant 2019;38:493-503.

17. Verleden SE, Vanaudenaerde BM, Emonds MP, Van Raemdonck DE, Neyrinck AP, Verleden GM, et al. Donor-specific and -nonspecific HLA antibodies and outcome post lung transplantation. Eur Respir J 2017;50:1701248.

18. Brugière $O$, Suberbielle $C$, Thabut G, Lhuillier E, Dauriat G, Metivier AC, et al. Lung transplantation in patients with pretrans- plantation donor-specific antibodies detected by Luminex assay. Transplantation 2013;95:761-5.

19. Hayes D Jr, Black SM, Tobias JD, Kopp BT, Kirkby SE, Mansour $\mathrm{HM}$, et al. Influence of human leukocyte antigen mismatching on bronchiolitis obliterans syndrome in lung transplantation. J Heart Lung Transplant 2016;35:186-94.

20. Kauke T, Kneidinger N, Martin B, Dick A, Schneider C, Schramm $\mathrm{R}$, et al. Bronchiolitis obliterans syndrome due to donor-specific HLA-antibodies. Tissue Antigens 2015;86:178-85.

21. Jaramillo A, Smith MA, Phelan D, Sundaresan S, Trulock EP, Lynch JP, et al. Development of ELISA-detected anti-HLA antibodies precedes the development of bronchiolitis obliterans syndrome and correlates with progressive decline in pulmonary function after lung transplantation. Transplantation 1999;67:1155-61.

22. Zazueta OE, Preston SE, Moniodis A, Fried S, Kim M, Townsend $\mathrm{K}$, et al. The presence of pretransplant HLA antibodies does not impact the development of chronic lung allograft dysfunction or CLAD-related death. Transplantation 2017;101:2207-12.

23. Kim SY, Jeong SJ, Lee JG, Park MS, Paik HC, Na S, et al. Critical care after lung transplantation. Acute Crit Care 2018;33:206-15.

24. Vigneswaran WT, Garrity ER Jr, Odell JA. Lung transplantation: principles and practice: CRC Press; 2016.

25. Wang Y. ABO-incompatible organ transplantation: Springer Singapore; 2019.

26. Kim M, Townsend KR, Wood IG, Boukedes S, Guleria I, Gabardi S, et al. Impact of pretransplant anti-HLA antibodies on outcomes in lung transplant candidates. Am J Respir Crit Care Med 2014; 189:1234-9.

27. Song EY, Lee YJ, Hyun J, Kim YS, Ahn C, Ha J, et al. Clinical relevance of pretransplant HLA class II donor-specific antibodies in renal transplantation patients with negative T-cell cytotoxicity crossmatches. Ann Lab Med 2012;32:139-44.

28. Tinckam KJ, Keshavjee S, Chaparro C, Barth D, Azad S, Binnie M, et al. Survival in sensitized lung transplant recipients with perioperative desensitization. Am J Transplant 2015;15:417-26.

29. Lau CL, Palmer SM, Posther KE, Howell DN, Reinsmoen NL, Massey HT, et al. Influence of panel-reactive antibodies on posttransplant outcomes in lung transplant recipients. Ann Thorac Surg 2000;69:1520-4.

30. Snyder LD, Gray AL, Reynolds JM, Arepally GM, Bedoya A, Hartwig MG, et al. Antibody desensitization therapy in highly sensitized lung transplant candidates. Am J Transplant 2014;14:849-56.

31. Gammie JS, Pham SM, Colson YL, Kawai A, Keenan RJ, Weyant RJ, et al. Influence of panel-reactive antibody on survival and rejection after lung transplantation. J Heart Lung Transplant 1997;16: 408-15.

32. Valenzuela NM, Reed EF. Antibodies in transplantation: the effects of HLA and non-HLA antibody binding and mechanisms of injury. Methods Mol Biol 2013;1034:41-70.

33. Otten HG, Verhaar MC, Borst HP, van Eck M, van Ginkel WG, Hené RJ, et al. The significance of pretransplant donor-specific antibodies reactive with intact or denatured human leucocyte antigen in kidney transplantation. Clin Exp Immunol 2013;173:536-43.

34. Pena JJ, Bottiger BA, Miltiades AN. Perioperative management of bleeding and transfusion for lung transplantation. Semin Cardiothorac Vasc Anesth 2020;24:74-83.

35. Babel N, Gabdrakhmanova L, Hammer M, Rosenberger C, Oppert M, Volk HD, et al. Induction of pre-transplant Epstein-Barr virus (EBV) infection by donor blood transfusion in EBV-seronegative recipients may reduce risk of post-transplant lymphoproliferative disease in adolescent renal transplant patients: report of two cases. Transpl Infect Dis 2005;7:133-6. 